\title{
Study on the Current Situation and Countermeasures for Agricultural Information Construction in China
}

\author{
Songlin Wang ${ }^{1}$, Wengang $\mathrm{Yu}^{2}$, Zhengqun $\mathrm{Mo}^{3}$ and Guohua $\mathrm{Fu}^{4}$ \\ ${ }^{1}$ College of Agriculture, Hainan University, 570228, Haikou, Hainan, P.R.China \\ ${ }^{2}$ College of Horticulture and Landscape Architecture, Hainan University, 570228, Haikou, Hainan, P.R.China \\ ${ }^{3}$ Agricultural Department of Hainan Province, 570204 Haikou, Hainan \\ ${ }^{4}$ Hainan University, 570228, Haikou, Hainan, China \\ 64238704@qq.com,yuwg2008@163.com,mzq123456789@sohu.com,fgh328@163.com
}

\begin{abstract}
Modern information technology today is penetrating into the line of agriculture and will play an important role in agricultural infomationization. As a symbol and key factor to modern agriculture, infomationization orients future agriculture and will sure to advance economy development and income in rural areas. There are many problems, however, exist during this process, effective counter measures shall be taken to guarantee the agricultural infomationization. From the view of agriculture in China, problems of agriculture were analyzed. A new and standardized model of agricultural industry chain was constructed. Operation mode of informatization management system of agricultural industry chain based on electronic commerce was put forward as well as expounded with a case.
\end{abstract}

Index Terms - Agricultural informationization, Problem; Countermeasure, Electronic commerc

\section{Introduction}

In recent years, as international agriculture competition aggravate. The comparative advantage of China's main agricultural products gradually decline.

Especially in some underdeveloped areas is still decentralized production, supply, the farmers don't have their own integration organization for supply and sale. The demand information is ineffective, production cost is high, which difficult to adapt to market needs. In this situation, the agriculture industry chain as a new form of management arises at the historic moment. The biggest challenge that this kind of management system facing in the process of agricultural industrialization is how to integrated the participants' organization management form on the supply chain with different form participants. Take the unified management strategy to the entire value chain. Agricultural informationization system which based on the e-commerce platform can solve the problem very well. It is gradually become the driver to promote the structural adjustment of China's rural economy and rural social comprehensive progress, which optimizes the allocation of resources and improve the economic benefits [1]. Agricultural informationization is an organic part of national informatization strategy. Agricultural informationization refers to comprehensive develop and application of modern information technology, to infiltrate into agricultural production, market, consumption and rural society, economy, technology and so on each concrete link, accelerate traditional agriculture transformation, greatly improve the efficiency of agricultural production and the level of agricultural productivity, promote agriculture sustainable, stable and efficient development process in the field of agricultural. Agricultural informationization is of great significance.

In the 21st century is the era of knowledge economy. Knowledge will become the dominant factor of economic development. Conventional wisdom is that the development of agricultural depends on the innovation of the biotechnology development. New information technology represented by computer technology is challenge to the understanding of the traditional. The development of agriculture is increasingly depends on the biological and information technology systems [2]. The rapid development of information technology to promote biotechnology to the realistic productivity transformation plays a huge role, internationally has the agricultural informationization as an important content of agricultural modernization and signs. The party's 16th national congress explicitly proposed "vigorously promote information technology, accelerate the construction of modernization". As a traditional agricultural country, the key to strengthen the construction of agricultural information system in our country use the informationization to promote agricultural modernization.

\section{The Information Construction Significance of Agriculture}

\subsection{Agricultural informatization is the foundation of the} agricultural modernization

\subsubsection{Agricultural informatization is the key way to optimize} the allocation of resources, improve resource utilization, increasing the income of agricultural producers

In today's globalization economic, agricultural policy and its information changes both at home and abroad, the recent development and prospects of WTO multilateral trade information, and agricultural producers are all of great value to optimize allocation of resources. In the process of agricultural production, the way to improve resource utilization, increase the income of agricultural producers only by the reasonable use of resources.

\subsubsection{Agricultural informationization is the indispensable way} to improve the management level of agricultural production, operation management level, and increase farmers' income

In the past, farmer's planting; breeding and habits are all 
under the government's plans lack of market information. Because of the ineffective of information, planting, breeding sales blindly cause the ups and downs of sideline farm production, and sold grain difficult, sell pigs difficult problems occur. With the emergence of agriculture information network, many smart farmers are use of agricultural information resources, production and sales of agricultural and sideline products, no longer blind production, learn the use of information, thus greatly improving the efficiency of agricultural production and management level.

\subsubsection{The important condition of agricultural informatization} is to reduce market risk, improve the efficiency of agricultural market circulation, and increasing farmers' income

Agricultural information is the lubricant of agricultural market economy, which plays the guider of the agricultural products market and the role of agricultural production arrangement. It also can make the both markets directly linked, which can largely reduce the circulation, simplifies trading programs, saving transaction costs. Have real trading information in timely and accurate basis, can reduce the blindness and hysteresis quality, reduce market risk, and greatly improve the efficiency of agricultural market circulation.

\subsubsection{Agriculture informationization is the way to improve the quality of the agricultural labor force, improve agricultural employment structure, and realize the transfer of rural labor force}

Through the carrier of the agricultural informatization, the quality of contemporary peasants is greatly improved. The import of information technology, can bring the agricultural industrial upgrading, improve agricultural employment structure, make fewer and fewer people engaged in agricultural production, and more and more labor people engaged in the intelligence information technology knowledge, which effective transfer part of the labor force.

\subsubsection{Agricultural informationization plays an important role in improving the integrate of agriculture and education, and accelerate agricultural production technology spread and popularization}

Agricultural informatization promotes the integrate of agriculture and education, which can not only make the coordination of agricultural production, scientific research and education departments of normal work of the organic, prompt suggests all aspects in a market economy for their respective position and organic combination mutual promotion, and will help spread of agricultural technology and information technology. Through the internet and multimedia technology information technology can be rapidly spread, farmers are in urgent need of the technology of professional experience in production technology and the latest application, break the time and space limit, speeds up the agricultural technology promotion.

\subsection{The problem of agricultural informatization}

China is a traditional agricultural country, the advantage of agriculture in the international market mainly relies on natural resources and low labor costs. Along with the development of the world new technology, the proportion of the technical content in agricultural products is more and more big, and agriculture in our country mainly small-scale peasant self-employed mode, does not produce economies of scale, thus the traditional prices advantage rely on low cost is gradually weakened. This makes the contradiction between "small farmers and big market" becomes more and more prominent, mainly manifested in the following aspects ${ }^{[2]}$.

(1) Blind prenatal program. Because of the variety agricultural crop and hybrid, producers tend to rely on theirs own experience to choose production project, determine the scale of production, rather than through the market survey, evaluation and forecast the plan production. Thus lead to agricultural production arrangement is passive, resulting in some agricultural products output and price fluctuations is bigger, affect the overall stability of agricultural production and farmers' enthusiasm.

(2) Without service assurance during the produce. In the process of production will involve the production factors of seeds, fertilizers, pesticides, agricultural machinery, and planting technology. The farmers because of the limitation of their own conditions can't invest a lot of manpower and financial resources to get related information, and carries on the selection, processing and application, which increases the cost of production and reduces the farmer's competitiveness.

(3) Narrow sales channel after produce. The broad masses of farmers because of the small scale of production can not enter the market directly; can not use market positioning, product brand packaging, services and promotions, and other means. Therefore, in the process of trading, the access to information and master often at a disadvantage, their interests are vulnerable to loss. To solve this contradiction must conduct the effectively agricultural industry chain management. We can link the supply of agricultural production and agricultural products production, processing, storage and transportation and sales into an organic whole based on market-oriented, efficiency as the center. At the same time, we can organize the people, goods, content, and information and technology elements' flow, coordination and control, optimize the combination of various factors of production, in order to obtain the value of the product value [3]. That is to say, we will establish a set of effective mechanisms for connecting the units in agricultural industrial chain management means. Based on the ecommerce platform of agricultural informationization system can make the enterprise and farmers, production and marketing closely relates in together, forms a complete industrial chain. So as to ensure the farmers with: antenatal plan guidance, service guaranty during production and sales channel with grantee after produce [4-5]. 


\section{The Construction Methods of Agricultural Informatization}

\subsection{Agricultural industrial chain enterprise management model}

Agricultural production and circulation process are involved in the production of agricultural industry chain. The processing required for raw materials suppliers, manufacturers, wholesalers, retailers and ultimately consumers network of supply and demand. However, how to build? Who will build? Are the unsolved problems on the basis of traditional agriculture modern agriculture industry chain?
In the whole agricultural industry chain has many operators, including farmers, material suppliers, leading enterprises, wholesalers, retailers, customers, etc. Among them, the leading enterprise is the most powerful stakeholders in the industrial chain. Its production scale, production capacity is strong. It has advanced management concept, modern technology level and rich market experience, and should be in the leading position in the industry chain ${ }^{[6]}$. With leading enterprises as the core to build the agricultural industrial chain operating model is shown in figure 1 .

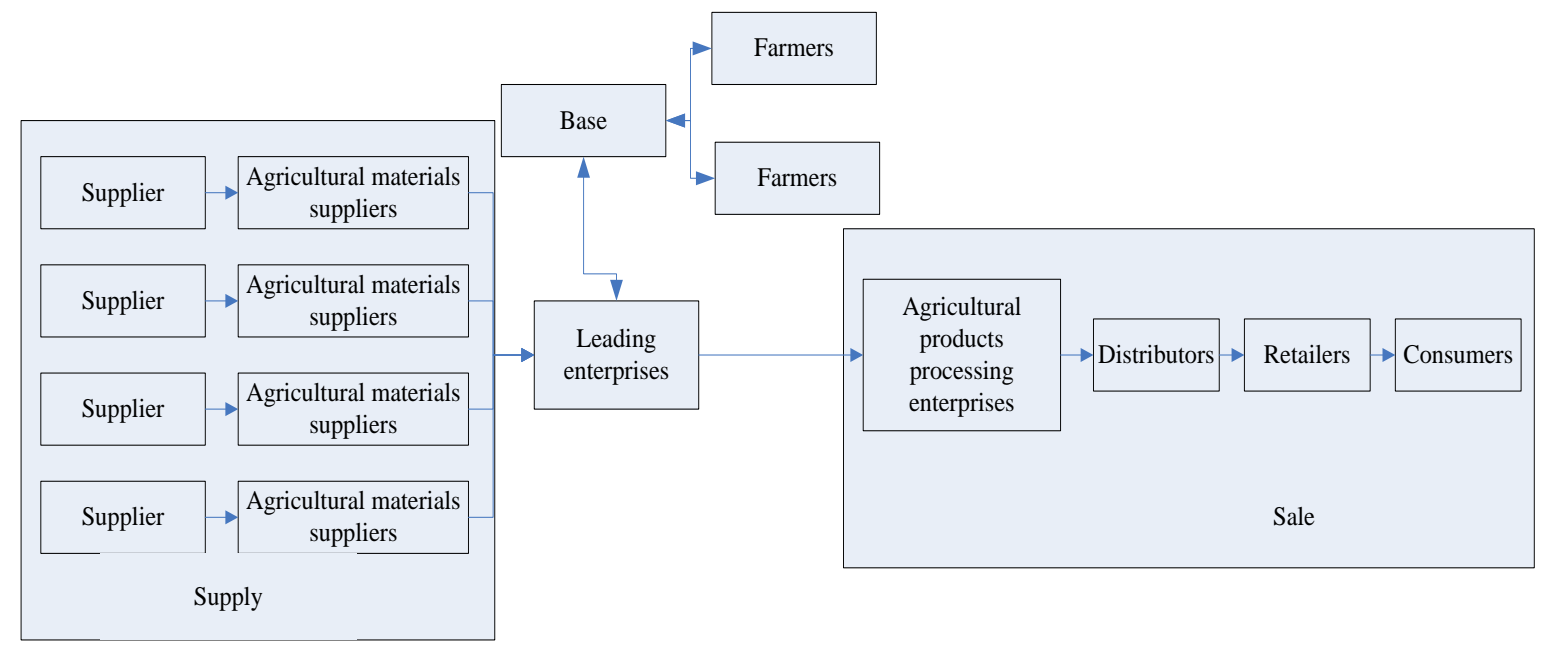

Fig. 1 Agricultural industry chain with leading enterprise as a core

\subsection{Virtual market operation model based on e-commerce}

In agriculture for large-scale development of industrialization and at the same time, enterprise management must be synchronized with agricultural production development. The informatization construction is the only way to improve the enterprise management [7-8]. More and more enterprise management information system will be the enterprise internal resources integration, to solve the agricultural industry chain management problem of the optimization of internal resources; And the implementation of e-commerce in the agricultural industry chain of each enterprise efficient cooperation, so as to realize the people of the whole industry chain, logistics, cash flow, information flow of the network management, provides a reliable technical guarantee for the agricultural industry chain management[9]. In this mode, the industrial chain of each link in the agricultural enterprise can through the electronic commerce platform in the virtual market registration information, and then login to agricultural e-commerce platform, looking for partner, with two-way choice for network transactions or business negotiations, so as to realize the connection of the industrial chain (Figure 2).

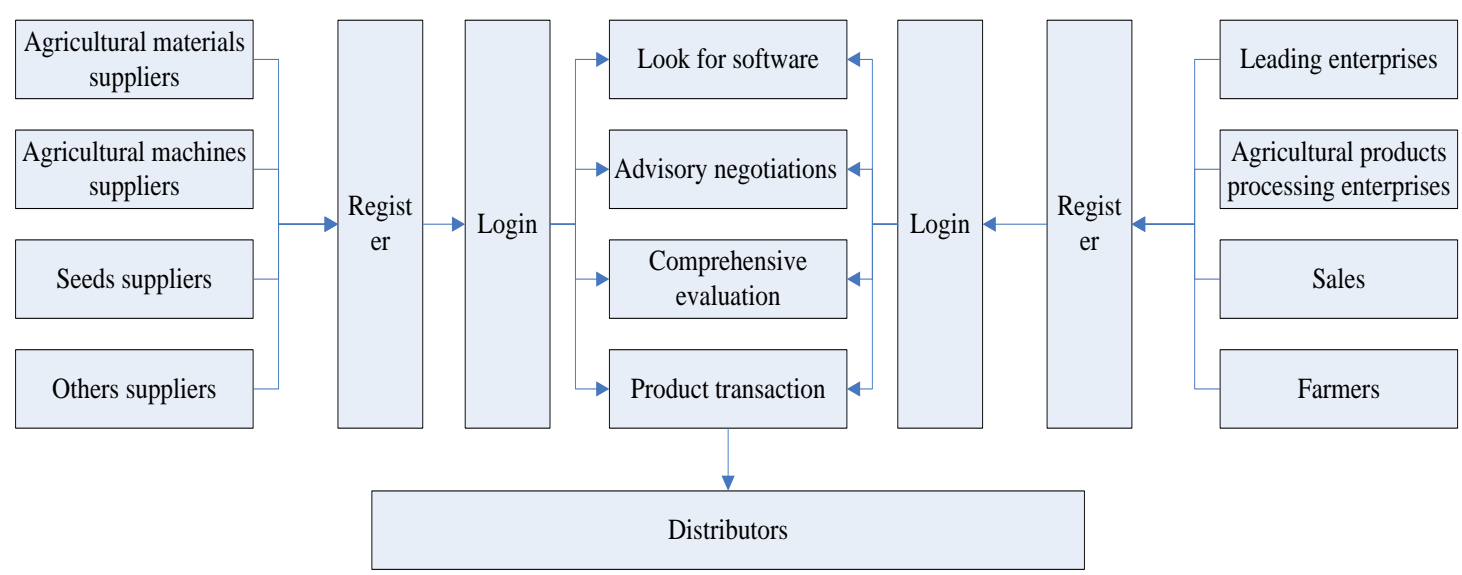

Fig. 2 Virtual market operation model based on e-commerce 


\section{The Application of the Methods}

Based on the above model, the author will illustrate the agricultural enterprise information system mode with a potato industry chain as an example [10]. Potato industry chain process is shown in Figure 3.

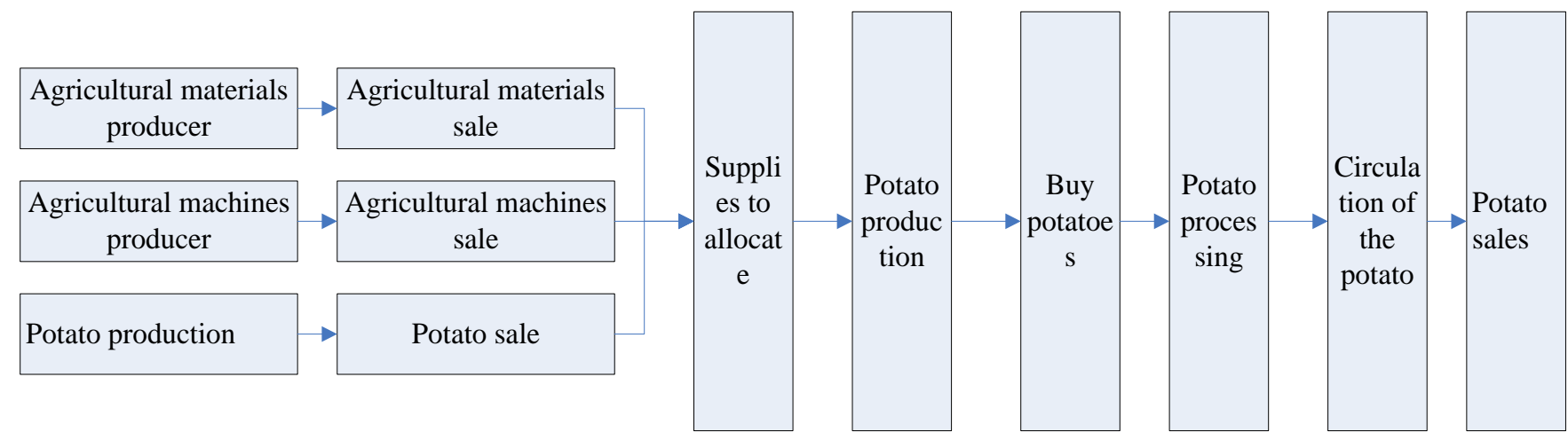

Fig. 3 Potato industry chain process

The outside enterprises in industrial chain on each node establish connections with other nodes on the chain enterprise through the electronic commerce platform, and realize the industrial chain link. The implementation of the physical model is as shown in figure 4 .

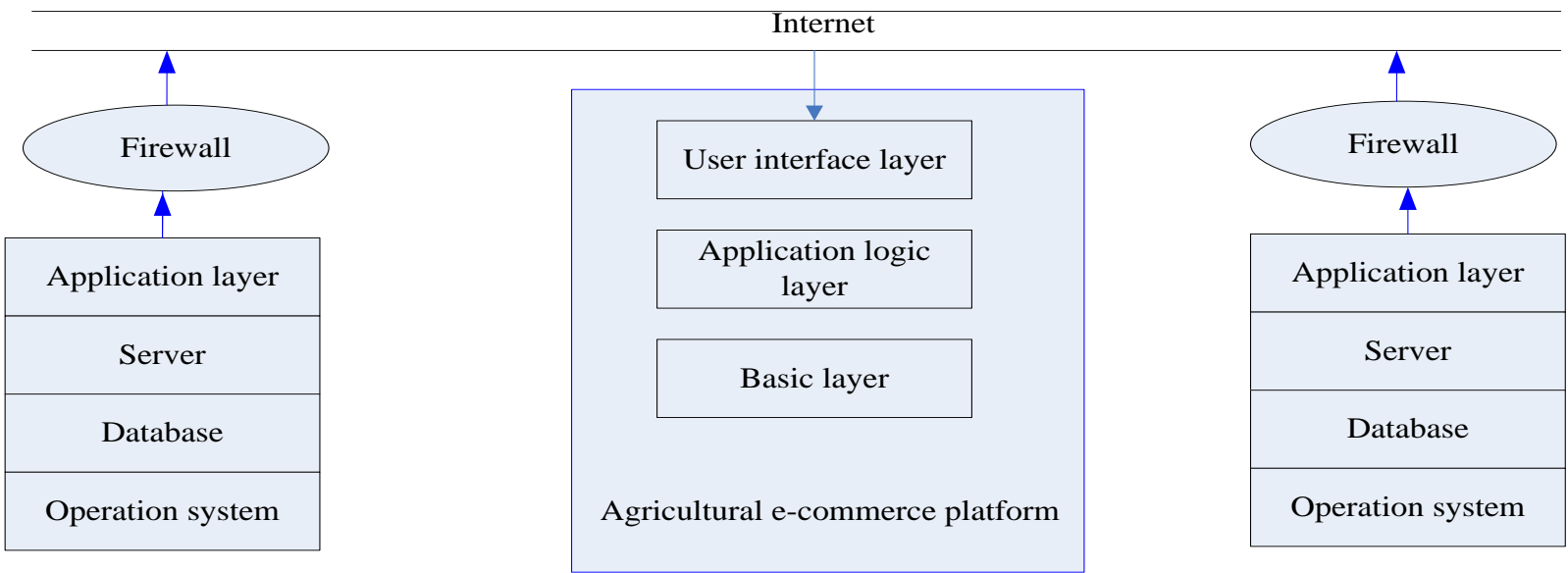

MIS management system
MIS management system

Fig. 4 Physical model of realizing industry chain connection

The MIS management information system is established in the industrial chain node enterprises according to their own characteristics. Its position in the industrial chain and realize the integration of the enterprise internal resources. Because the industry chain contains more node enterprise, therefore, the information system is established only take the leading enterprises in potato industry chain. The example is in figure 5.

At present, the system has been completed and put into use, its planning and scheduling in enterprise has played an important role, and inventory management, etc. 


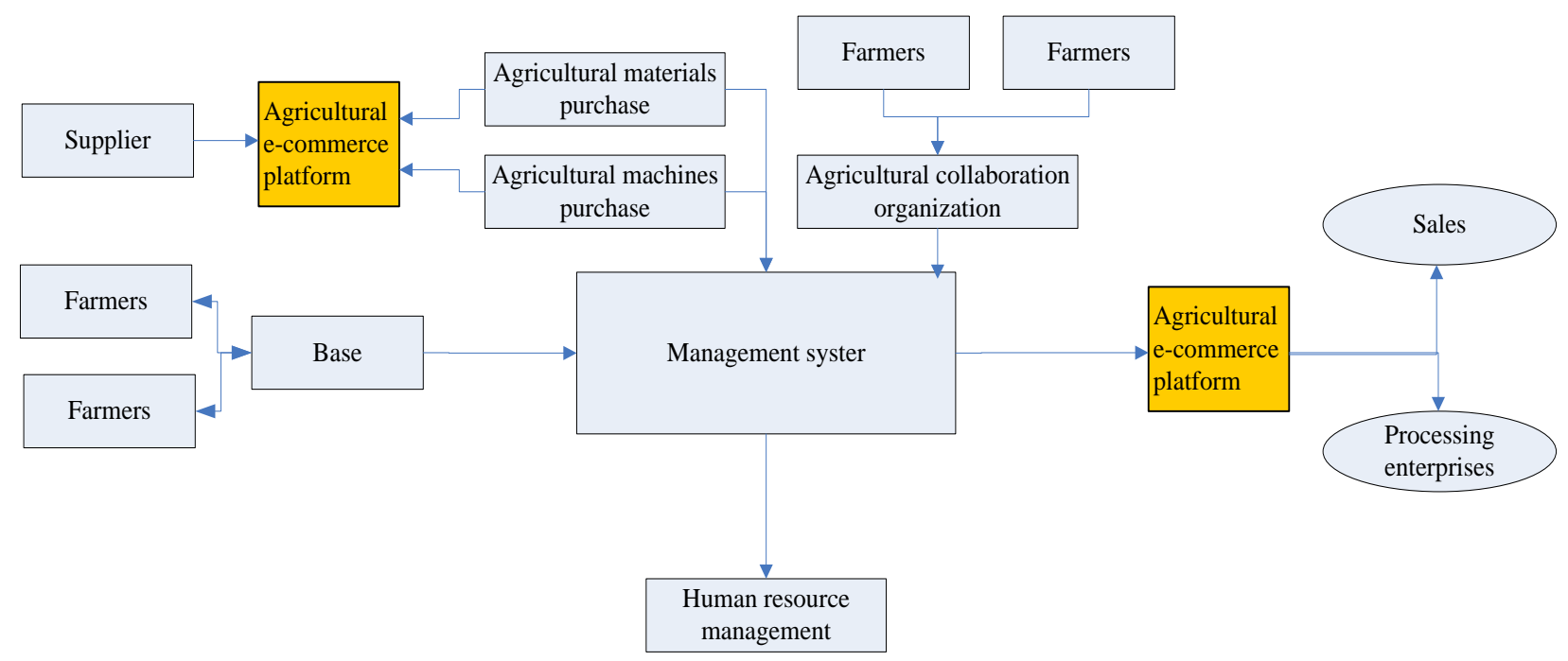

Fig. 5 Leading enterprise of information system

\section{Conclusions}

Modern agriculture is a comprehensive agriculture containing the concept of modern technology and modern development. Agriculture information system based on electronic commerce eliminates the time and space obstacle; effectively increase the income of the agricultural enterprises and farmers, breakthrough the bottleneck of the agricultural products from small farmers towards large market, which is the only way to realize agricultural modernization and rural information.

\section{References}

[1] Chen Xinghua. The evolution of agricultural informationization and countermeasures. Science and technology management research, 2009 (7): 437-03.

[2] Cao Yong. To speed up the agricultural informationization construction to promote agricultural modernization development. Journal of Inner Mongolia science and technology and economy, 2009 (9): 63-64, 18.

[3] Zhao chun. Henan province rural informatization way and strategy analysis. Journal of management informationization in China, 2009, 12 (17): 81-83.

[4] Du Xulin Zhu Qin, Wen Huaiyu. New rural informationization present situation and development countermeasures. Rural economy, 2009 (8): 95-98.

[5] HUANGSH, SHEORANSK, WANGG. A review and analysis of supply chain operations reference (SCOR) model. Supply Chain Management, 2004, 9(1):23- 29.

[6] CHOITY, DOOLEYKJ. Supply networks and complex adaptive systems: control versus emergence. Journal of Operations Management, 2001, 19 (3):351- 366.

[7] Zhang Ailing. What time thinking about the construction of speed up agricultural informationization. Journal of agricultural science and technology, 2007 (1): 17-18.

[8] Yang Xiaorong. Thinking about China's rural informatization construction. World agriculture, 2008 (3): 19-21.

[9] Jiang Xiangdong. Strategy analysis of agricultural informatization development. Journal of agricultural mechanization research, 2005 (3): 32-35.

[10] Liu WanDai. Ma Xinming. Agricultural information technology development research in the construction of new socialist rural. Agricultural science of Anhui, 2006, (12): 2911-2912. 